\title{
18. Using MOVE (1)
}

MOVE can be used to copy the contents of one memory location to another - or to move a particular value to a location.

\section{e.g.(1) DISPLAY 'EMPLOYEE'S WAGE IS AT PRESENT ' WAGE DISPLAY 'WHAT IS EMPLOYEE'S NEW WAGE ?' ACCEPT NEW-WAGE MOVE NEW-WAGE TO WAGE.}

(Displays present wage on screen, asks for new wage and then brings WAGE up to date).

e.g.(2) MOVE 20 TO NUMBER-OF-STUDENTS.

(Makes NUMBER-OF-STUDENTS equal 20).

e.g.(3) MOVE 'A \& B COMPUTERS' TO NAME-OF-FIRM.

(Note the speech marks around an alphanumeric value).

It is important - when moving data from one field to another - to make sure that the movement is allowed. For example - alphabetic data cannot be moved to a numeric field (or vice versa).

It is also necessary to ensure that the data will fit into the field to which it is being copied - otherwise part of it will be lost.

\section{Exercise}

1. Write statements to carry out the following:

a) make WAGE equal 8000 ;

b) make BONUS equal 100;

c) make PAY equal WAGE;

d) fill location AGREED with the word 'YES';

e) make STUDENT-MARK equal 0.

2. Write a program that will ask for an employee's name and wage and store the data in a Central Memory area whose overall-name is OLD-STAFFRECORD (see lesson 9); then copy it to another area called NEWSTAFF-RECORD, add 10\% to the wage and display the new information.

3. Write a program which will ask for a student's name and subject studied, and store it in a data item whose overall name is STUDENT-RECORD; then copy the data to a data item called EXAM-CANDIDATE-RECORD and display it. 